University of St. Thomas, Minnesota

UST Research Online

$11-2015$

\title{
The impact of financial histories on individuals and societies: A replication and extension of Berg et. al.
}

\author{
Brian P. Shapiro \\ University of St. Thomas, Minnesota, BPSHAPIRO@stthomas.edu \\ Xu Jiane \\ Duke University \\ Radhika Lunawat \\ Duke University
}

Follow this and additional works at: https://ir.stthomas.edu/ocbacctpub

Part of the Accounting Commons

This Article is brought to you for free and open access by the Accounting at UST Research Online. It has been accepted for inclusion in Accounting Faculty Publications by an authorized administrator of UST Research Online. For more information, please contact asle4660@stthomas.edu. 


\section{Emerald Insight}

\section{Replication in Experimental Economics}

The Impact of Financial Histories on Individuals and Societies: A Replication of and Extension of Berg et al. (1995)

Xu Jiang Radhika Lunawat Brian Shapiro

\section{Article information:}

To cite this document: Xu Jiang Radhika Lunawat Brian Shapiro . "The Impact of Financial Histories on Individuals and Societies: A Replication of and Extension of Berg et al. (1995)" In Replication in Experimental Economics. Published online: 13 Oct 2015; 95-135.

Permanent link to this document:

http://dx.doi.org/10.1108/S0193-230620150000018004

Downloaded on: 24 November 2015, At: 07:04 (PT)

References: this document contains references to 0 other documents.

To copy this document: permissions@emeraldinsight.com

The fulltext of this document has been downloaded 1 times since NaN*

Access to this document was granted through an Emerald subscription provided by Token:BookSeriesAuthor:DA3FF9C1-9A49-4D81-B3B1-691B53C4982C:

\section{For Authors}

If you would like to write for this, or any other Emerald publication, then please use our Emerald for Authors service information about how to choose which publication to write for and submission guidelines are available for all. Please visit www. emeraldinsight.com/ authors for more information.

\section{About Emerald www.emeraldinsight.com}

Emerald is a global publisher linking research and practice to the benefit of society. The company manages a portfolio of more than 290 journals and over 2, 350 books and book series volumes, as well as providing an extensive range of online products and additional customer resources and services.

Emerald is both COUNTER 4 and TRANSFER compliant. The organization is a partner of the Committee on Publication Ethics (COPE) and also works with Portico and the LOCKSS initiative for digital archive preservation.

*Related content and download information correct at time of download. 


\title{
THE IMPACT OF FINANCIAL HISTORIES ON INDIVIDUALS AND SOCIETIES: A REPLICATION OF AND EXTENSION OF BERG ET AL. (1995)
}

\author{
Xu Jiang, Radhika Lunawat and Brian Shapiro
}

\begin{abstract}
We replicate and extend the social history treatment of the Berg, Dickhaut, and McCabe (1995) investment game, to further document how the reporting of financial history influences how laboratory societies organize themselves over time. We replicate Berg et al. (1995) by conducting a No History and a Financial History session to determine whether a report summarizing the financial transactions of a previous experimental session will significantly reduce entropy in the amounts sent by Investors and returned by Stewards in the investment game, as Berg et al. (1995) found. We extend Berg et al. (1995) in two ways. First, we conduct a total of five sessions (one No History and four Financial History sessions). Second, we introduce Shannon's (1948) measure of entropy from information theory to assess whether the introduction of financial transaction history reduces the amount of dispersion in the
\end{abstract}

Replication in Experimental Economics Research in Experimental Economics, Volume 18, 95-135 Copyright $(C) 2015$ by Emerald Group Publishing Limited All rights of reproduction in any form reserved ISSN: 0193-2306/doi:10.1108/S0193-230620150000018004 
amounts invested and returned across generations of players. Results across sessions indicate that entropy declined in both the amounts sent by Investors and the percentage returned by Stewards, but these patterns are weaker and mixed compared to those in the Berg et al. (1995) study. Additional research is needed to test how initial conditions, path dependencies, actors' strategic reasoning about others' behavior, multiple sessions, and communication may mediate the impact of financial history. The study's multiple successive Financial History sessions and entropy measure are new to the investment game literature.

Keywords: Trust; investment; return; financial history; societal organization; entropy

JEL classifications: C92; C65; D80; D02

Despite the proliferation of measurement and reporting practices, little is known about their impact on society at large. The purpose of this paper is to replicate and extend the social history treatment of the Berg, Dickhaut, and McCabe (1995) investment game, to further document how a prevalent public disclosure practice, the reporting of financial history, influences how laboratory societies organize themselves over time. While the investment game has been widely studied and replicated, the social history treatment has not been as extensively examined (for an exception, see Ortmann, Fitzgerald, \& Boeing, 2000). We develop the idea that individuals and organizations may use information not only to draw inferences about their own and others' behavior, but also to restructure their environment. More specifically, we hypothesize that successive generations of laboratory societies will increasingly organize themselves over time when they receive reports of financial transactions undertaken by the preceding generation.

Theories of how communication influences the way societies organize themselves (e.g., Giddens, 1984; Habermas, 1979; Leydesdorff, 2001; Luhmann, 1986) provide a basis for our hypothesis. In these theories, societal organization is an emergent property of the norm-governed behavior of individual actors and can be mediated through various coordination and communications systems. For example, information systems that aggregate and publicly report the actions of individuals from a preceding generation can help organize the actions of individuals in a successive generation if individuals interpret the information as an indicator of the expected 
behavioral norms in their society (cf. Chaudhuri, Schotter, \& Sopher, 2009). In this manner, the public information that individuals use to produce and reproduce their social systems are the product of social interaction among individuals in preceding generations (cf. Berg et al., 1995, pp. 132-133; Giddens, 1984; Latour, 1993).

We operationally define an increase in societal organization as a reduction in the entropy (disorder or variance) in the amounts invested and returned by Investors and Stewards across successive generations of players in an Investment Game setting. In an Investment Game, an Investor receives $\$ 10$ from the experimenter and then decides how much of the $\$ 10$ $(\$ 0-\$ 10)$ to send to the Steward. The amount sent to the Steward then triples $(\$ 0-\$ 30)$. Finally, the Steward decides how much of the tripled sum to send back to the Investor. In our experiment, each societal generation consists of a new set of Investor/Steward pairs. Following Berg et al. (1995), we introduce financial history by providing each successive generation with a summary of the amounts invested and returned by players in the preceding generation. We replicate Berg et al. (1995) by conducting a No History and a Financial History session in order to determine whether a report summarizing the financial transactions of a previous experimental session will significantly reduce entropy in the amounts sent by Investors and returned by Stewards, as the Berg et al. (1995) study shows. We also extend Berg et al. (1995) in two principal ways. First, in order to test our hypothesis that successive generations of laboratory societies will increasingly organize themselves when they receive a financial report of transactions from the immediately preceding generation, we conduct a total of five sessions (one No History and four Financial History sessions). Second, we introduce Shannon's (1948) measure of entropy from information theory to assess whether the introduction of financial transaction history reduces entropy (the amount of dispersion) in the distributions of amounts invested and returned across generations of players.

The relatively simple and widely used setting of the Investment Game has several attractive features for investigating the evolution of societal organization. The game is played only once, Investors and Stewards are anonymously paired, and anonymity ensures that the experimenter cannot match the identities of specific individuals to the dollar amounts sent and returned. These procedures control for alternative explanations of behavior including repeated game reputation effects, contractual precommitments, punishment threats, and experimenter demand effects (e.g., Ortmann et al., 2000). In addition, in the Investment Game and other similar games (e.g., the gift exchange game, the peasant-dictator game, and the 
moonlighting game), many players invest and return nonzero amounts, contrary to the assumption of pure monetary self-interest (Berg et al., 1995; Camerer \& Fehr, 2002; Cox, 2004; Dickhaut \& McCabe, 1997; for a metaanalysis of the Investment Game, see Johnson \& Mislin, 2011). Finally, in the Investment Game setting, substantial variation exists across the actions of different players (e.g., Berg et al., 1995; Johnson \& Mislin, 2011; Ortmann et al., 2000). Following Berg et al. (1995), we hypothesize that the introduction of a financial transaction history will reduce this variation by mediating what individuals expect of others and what others expect of them. In addition, we extend Berg et al. (1995) by further hypothesizing that with financial histories given to successive generations of laboratory societies, the actions of individuals will on average converge across those societies toward emerging norms of expected behavior.

In sum, our study attempts to replicate Berg et al.'s (1995) results and extends the prior investment game literature in two principal ways. First, it applies our entropy metric to the Berg et al. (1995) data. Second, it ascertains whether the introduction of a financial history has an incremental effect across multiple generations of the investment game.

The remainder of the paper is organized as follows. The first section describes the Investment Game, develops our measure of entropy, and states our hypotheses. The subsequent two sections present the experimental method and results, respectively. The concluding section discusses the implications of our results and identifies opportunities for future research.

\section{THEORY AND HYPOTHESES}

Below we describe the Investment Game and develop our hypotheses about entropy reduction and societal organization.

\section{Investment Game Structure}

The investment game is played as follows. In stage one, the subjects in Rooms A and B are each given $\$ 10$ as a show-up fee. Subjects in Room A (Investors) are given an additional $\$ 10$ and must decide how much of their $\$ 10$ to send to an anonymous counterpart in Room B. We denote this amount by $M_{\mathrm{a}}$. The amount sent is then tripled to $3 M_{\mathrm{a}}$. In stage two, a counterpart in Room B (the Steward) is given the tripled money. The 
counterpart Steward must decide how much money to return, which is denoted $k_{\mathrm{b}}\left(3 M_{\mathrm{a}}\right)$. The Investor chooses the strategy $M_{\mathrm{a}} \in\{0,1,2, \ldots, 10\}$, while the Steward chooses the strategy:

$$
k_{\mathrm{b}}:\{0,3, \ldots, 30) \rightarrow\{0,1, \ldots, 30\}
$$

which satisfies $0 \leq k_{\mathrm{b}}\left(3 M_{\mathrm{a}}\right) \leq 3 M_{\mathrm{a}}$.

These strategies result in the payoffs:

$$
P_{\mathrm{a}}\left(M_{\mathrm{a}}, k_{\mathrm{b}}\right)=\$ 10+\left(\$ 10-M_{\mathrm{a}}\right)+k_{\mathrm{b}}\left(3 M_{\mathrm{a}}\right)
$$

and

$$
P_{\mathrm{b}}\left(M_{\mathrm{a}}, k_{\mathrm{b}}\right)=\$ 10+3 M_{\mathrm{a}}-k_{\mathrm{b}}\left(3 M_{\mathrm{a}}\right)
$$

A subject's initial wealth is denoted $W_{i}$. If subjects have strictly increasing indirect utility function for wealth, given by $V_{i}\left(W_{i}+P_{i}\left(M_{\mathrm{a}}, k_{\mathrm{b}}\right)\right)$ for $i=\mathrm{a}$, $\mathrm{b}$, and each subject, $i$, maximizes $V_{i}(\cdot)$, then Stewards have a dominant strategy to keep all the money, that is, $k_{\mathrm{b}}\left(3 M_{\mathrm{a}}\right)=0$ for all $M_{\mathrm{a}}$. If Investors infer their counterpart's dominant strategy, then they should send nothing, that is, $M_{\mathrm{a}}=0$. If these results obtain, societal entropy will be zero, even in the absence of information about the actions of individuals in a preceding laboratory society.

\section{Hypotheses}

One hypothesis for the investment game is that subjects will make decisions consistent with the subgame perfect prediction,

$N_{0}: M_{\mathrm{a}}=0$ for all a

If for some reason Investors send a positive amount (i.e., $M_{\mathrm{a}}>0$ ), then the dominant strategy for Stewards is as follows:

$$
N_{1}: \text { If } M_{\mathrm{a}}>0 \text {, then } k_{\mathrm{b}}\left(3 M_{\mathrm{a}}\right)=0 \text { for all } \mathrm{b}
$$

Past research in the Investment Game has found, however, that some investors trust stewards and that some stewards are trustworthy (Berg et al., 
1995; Cox, 2004; Johnson \& Mislin, 2011; Ortmann et al., 2000). Consistent with these prior results, our hypotheses for the No History condition (first generation of players) in our Investment Game are as follows:

H1. Investors will send nonzero amounts to Stewards $\left(M_{\mathrm{a}}>0\right.$ for some "a").

H2. Stewards who receive nonzero amounts will return nonzero amounts to Investors $\left(k_{\mathrm{b}}\left(3 M_{\mathrm{a}}\right)>0\right.$ for some "b").

\section{Impact of Financial History}

The question next arises as to how much variation exists across individual behavior, and whether a simple information system that merely aggregates and reports the actions of individuals from a previous generation will reduce that variation in a successive generation. Berg et al. (1995) previously reported less variation between a No History and one subsequent Social History session. We attempt to replicate this result as well as test our general hypothesis that when financial histories are provided to successive generations of laboratory societies, the actions of individuals will on average converge across those societies toward emerging norms of expected behavior.

In our experimental setting, all generations except the first receive a financial history of transactions made by the immediately preceding generation. Sociological research suggests that communication across generations can significantly influence behavior in subsequent generations (e.g., Giddens, 1984; Habermas, 1979; Leydesdorff, 2001; Luhmann, 1986; see also Chaudhuri et al., 2009), which documented the conditions under which intergenerational communication improves coordination in the Minimum Effort Game setting. In addition, Lunawat (2013a, 2013b) used the Berg et al. (1995) setting to show how communication of private financial information can enhance trust between a manager and an investor. In our setting, a financial history summarizing the transactions of a preceding generation may provide a basis for individuals to assess the dispositions, intentions, and trustworthiness of players in a subsequent Investment Game (cf. Kramer, 1999, p. 575). For example, Investors might use the past transaction data to identify investments that are likely to yield a positive return, ${ }^{1}$ and Stewards might infer the reasonableness of the amount invested by their Investor partners as well as the amount they are expected to return to the Investors. Alternatively, Investors and Stewards might more simply select amounts based on their conformity with perceived 
central tendencies in the past data, regardless of whether the central tendencies are socially beneficial.

\section{Using Entropy to Measure the Impact of Financial History}

To assess the impact of financial history on players' behavior, we measure the change in entropy of the amounts invested and returned by Investors and Stewards. The term entropy first arose in statistical mechanics to reflect the status of a particle system. Decreases in entropy reflect less movement in the particle and less uncertainty about its location. In a social setting, the amount of entropy reflects the amount of uncertainty about individuals' behavior. An increase in entropy means that the behavior of individuals is more uncertain, while a decrease in entropy means that the behavior is less uncertain or more orderly.

The entropy concept has been widely used in the engineering and information theory literatures (e.g., see Cover \& Thomas, 1991). Sims (1998, 2003, 2005) subsequently introduced Shannon's (1948) entropy concept in the economics literature and defined the informativeness of information signals as the change in entropy between prior and posterior distributions. The entropy concept has been used to model price stickiness (Sims, 1998), flexible information acquisition (Yang, 2015), and general equilibrium (Mackowiak \& Wiederholt, 2009). Following these prior studies, we use the entropy concept to measure the amount of uncertainty about individuals' behavior.

More formally, we define the amount of order in our laboratory societies as follows. Let $p_{i}$ denote the probability of the $i$ th element being drawn from a distribution of $n$ discrete outcomes. Entropy is defined by $-\sum_{i} p_{i} \log _{2} p_{i}$. As an example, consider a binary outcome such as the flip of a coin. A fair coin has entropy equal to 1 , and a biased coin with a 0.75 probability of heads has entropy equal to $0.81 .^{2}$ The entropy metric indicates that the biased coin has more order than the fair coin. ${ }^{3}$

\section{Entropy Metric Applied to the Berg et al. (1995) Data}

To illustrate how the entropy metric can be applied and to establish continuity with the prior literature, we now perform an entropy analysis of the Berg et al. (1995) data. The Berg et al. (1995) study had two treatments, "no history" and "social history." The social history treatment included a report summarizing the decisions in the no history treatment. Below, we re-label their "social history" treatment as "financial history" to conform 
to the labels we use in our experiments. We compare the entropy metrics across the Berg et al. (1995) no history and financial history treatments, separately for the investor, steward, and joint data sets.

For the Investors, Entropy ${ }_{\text {No History }}=3.141$ and Entropy $y_{\text {Financial History }}=$ 2.876. We used a bootstrapping technique to determine whether the observed Entropy reduction of 0.265 is statistically significant. The null hypothesis for this test is that the amounts invested were chosen randomly. For this and all subsequent tests reported below, we generated 10,000 measures of differences in entropy. Based on the bootstrapped distribution, the observed reduction in entropy is significant ( $p<.02$, one-tailed).

Since the maximum amounts returned by stewards were constrained by the tripled amounts sent by investors, we converted the amounts returned into percentages of the maximum amount that could be returned. Under this measure, more trustworthy stewards returned a higher percentage. More specifically, we analyzed the entropy in the distributions of the amounts returned by Stewards, in deciles of percentage of amounts received from Investors. For these Steward distributions, Entropy $\mathrm{No}_{\mathrm{Nistory}}=3.086$ and Entropy $y_{\text {Financial History }}=2.709$. A bootstrapped distribution indicates that the observed Entropy difference of 0.377 is statistically significant $(p<$ .0001 , one-tailed).

Finally, the Berg et al. (1995) no history and financial history data as a whole tended to cluster on outcome pairs. We examine the joint densities of Investor and Steward behavior to test whether the observed clustering is statistically significant. This test must take into account that the No History condition has a smaller sample size than the Financial History condition. Ceteris paribus, smaller sample sizes yield smaller maximum levels of entropy. ${ }^{4}$ The entropy formula for the No History condition is:

$$
-\sum_{i} \sum_{j} \frac{f_{i}, j}{32} \log _{2} \frac{f_{i}, j}{32}
$$

where $f_{i, j}$ denotes the frequency in category " $i, j$. " For example, "3,2" denotes 3 dollars invested and 2 returned by the steward. A similar formula applies to the Financial History condition, with 28 possible observations. The calculated entropies are 4.688 and 4.227 for the No History and Financial History conditions, respectively, for an overall decrease in entropy of 0.461 across the two conditions. Based on a bootstrapped distribution of the difference in entropies across the two conditions, the 0.461 reduction in entropy is marginally significant at the .055 level (one-tailed). 
In sum, the Berg et al. (1995) data indicate that the introduction of financial history significantly reduced entropy in the distributions of amounts sent and amounts returned, and marginally reduced entropy in the joint distributions. Below we attempt to replicate this result, as well as test whether financial histories will have an incremental effect over subsequent generations of laboratory societies. To address the latter, we gathered new data over five societal generations to test the predictive power of our hypothesis that financial histories provide a basis for developing order in societies. Participants in Session I (the first generation) received no financial history, whereas participants in Sessions II-V (the four subsequent generations) received a report summarizing the financial history of the immediately preceding session. Thus, Sessions I and II replicate the original Berg et al. (1995) study, and Sessions III-V extend that study.

Based on our preceding discussion of social theory and our entropy analyses of the Berg et al. (1995) data, the following hypotheses predict that the distributions of the amounts invested, returned, and their joint distributions will exhibit more order (less entropy) across generations of players:

H3. Financial transaction histories will produce more order (less entropy) in the Investor distributions across generations.

H4. Financial transaction histories will produce more order (less entropy) in the Steward distributions across generations.

H5. Financial transaction histories will produce more order (less entropy) in the joint Investor/Steward distributions across generations.

\section{METHOD}

\section{Subjects}

Subjects were recruited and participated in the experimental sessions in two groups separated by time and geography. Group 1 subjects were recruited in October 2007 from the subject pool in the CIRANO Research Center, Montreal, Canada. The CIRANO subject pool was comprised mostly of undergraduate and graduate students from the universities that participated in the research center. Due to a nondiscrimination clause governing subject recruiting, a few Group 1 subjects were nonstudent working professionals from the downtown Montreal area. Group 2 subjects were mostly 
undergraduate students recruited in February and March 2015 from the Experimental Social Sciences Lab at the University of California - Irvine.

The same experimental procedures were administered to both subject groups. Subjects received $\$ 10$ for showing up. Subjects also could earn up to an additional $\$ 30$, depending on their decisions and the decisions of their anonymous partner. Subjects were told to report directly to either Room A or Room B. Room A subjects served as Investors, and Room B subjects served as Stewards. A monitor was randomly chosen in each room after 10 subjects arrived. Monitors received $\$ 5$, in addition to their $\$ 10$ show-up fee.

Five sessions consisting of nine pairs of subjects and two monitors were run for both Group 1 and Group 2. The first session was the "No History" condition, in which subjects did not receive any financial history from a previous experimental session. The other four sessions received a financial history from the immediately preceding experimental session. The Appendix provides the instructions for both investors and stewards, for both the nonhistory and history conditions. Table 1 (Table 2 ) summarizes the results for each of the nine pairs of Group 1 (Group 2) subjects in each session.

\section{Materials}

Each subject was given a consent form and set of instructions. The consent form emphasized that (a) participation in the experiment will not affect participants' relationship with the University or affect their course grades, (b) participation is voluntary, (c) all data will remain confidential, and (d) compensation consists of a payment for showing up plus or minus amounts sent and received to anonymous counterparts in the experiment. The instructions were read aloud by the experimenter.

\section{Procedures}

The Appendix provides the instructions, including the procedures taken to assure anonymity and confidentiality. Each subject performed the following steps:

A. Subjects were randomly assigned to report directly to either Room A or Room B. One subject in each room was randomly selected to serve as a monitor (called Monitor A or Monitor B, for Room A and Room B, respectively). Monitors verified that the experimenters followed the experimental instructions. 
B. Subjects read the consent form, were asked questions about the form, were given an opportunity to ask questions about the form, and then signed the form if they wished to participate in the experiment.

C. An experimenter in Room A read the experimental instructions out loud in Room A, and another experimenter in Room B read the instructions out loud in Room B. Subjects in both rooms were given hard copies of the instructions and were asked to read along silently. Toward the end of the instructions, a summary financial history was given to all but the first generation of players.

D. One at a time, Room A subjects (Investors) were called to a private area in Room A, were randomly given an envelope containing \$10, opened the envelope, and decided whether to send all, some, or none of $\$ 10$ to their Room B counterparts (Stewards). Room A subjects put the amount of money they wish to send in an envelope and pocketed the rest. Room A subjects also pocketed a specially marked key to be used later.

E. After all Room A subjects performed step D, the Room A monitor took the envelopes to a recorder who was located in a hallway. The recorder recorded the amount sent and tripled the investment. The Room B monitor was then called to bring the envelopes to Room B, and Monitor A returned to Room A.

F. One at a time, Room B subjects were called to a private area in Room $\mathrm{B}$, were randomly given an envelope, opened the envelope, decided how much money to send back to their counterpart in Room A, left that amount of money in the envelope, and pocketed the rest. Afterward, each Room B subject was paid a $\$ 10$ show-up fee and was asked to leave the building.

G. The Room B monitor took the envelopes to the recorder in the hallway. At this time the amounts sent back were recorded. The Room A monitor was called to put the envelopes into mailboxes marked with letters corresponding to letters on the envelopes.

$\mathrm{H}$. One at a time, Room A subjects went to Room C and opened the mailbox with a lettered key corresponding to the letter on mailbox. After opening the appropriate mailbox, Room A subjects took out the envelope, removed the money, and dropped the key in a box. Afterward, Room A subjects were paid their $\$ 10$ show-up fee and were then asked to leave the building.

I. The monitors were paid $\$ 15$ for their participation. 


\section{Comparison with Berg et al. (1995)}

Besides the difference in subject pools, our experimental setting differs from the Berg et al. (1995) experiment in one respect. In the investment games reported in Berg et al. (1995), all subjects were given a $\$ 10$ show-up fee. Room A subjects then decided how much of their $\$ 10$ show-up fee to send to their anonymous counterpart in Room B, and Room B subjects pocketed their show-up fee. Our experiment followed the same procedures, except that Room A subjects also received an additional \$10 show-up fee.

\section{RESULTS}

Below we report the results for each hypothesis, for Group 1 followed by Group 2. We also report results where we combine both groups in footnotes.

\section{Amounts Invested and Returned}

Participants in Session I have no history, while participants in Sessions II-V have financial history because they have access to the results of prior sessions. H1 predicted that investors would send nonzero amounts to stewards. For Group 1, the average amount invested ranged from $\$ 4.67$ in Session I to $\$ 7.00$ in Session V (Table 1), with an overall average of $\$ 5.45$. One-sided Wilcoxon rank-sum tests indicate that in all five sessions, the amounts invested differed significantly from zero with a one-sided $p$-value $<.023$. For Group 2, the average amount invested ranged from $\$ 5.22$ in Session I to \$4.11 in Session V (Table 2), with an overall average of \$2.69. One-sided Wilcoxon rank-sum tests indicate that in all five sessions, the amounts invested differed significantly from zero with a one-sided $p$-value $<.054$. These results support H1. As a direct comparison with Berg et al. (1995), we also compare the amounts sent and returned between Session I (i.e., the generation without financial history) and Session II (i.e., the immediate generation that observes financial history). For Group 1, the average amounts sent for Sessions I and II are \$4.67 and \$5.22, respectively. For Group 2, the average amounts sent for Sessions I and II are $\$ 5.00$ and $\$ 2.67$, respectively. One-sided Wilcoxon rank-sum tests indicate that there is no statistical difference between the amounts sent of the two 
Table 1. Group 1 Amounts Sent and Returned, by Experimental Session.

\begin{tabular}{|c|c|c|c|c|c|}
\hline \multicolumn{3}{|l|}{ Session I } & \multicolumn{3}{|c|}{ Session II } \\
\hline Subject pair & Sent & Returned & Subject pair & Sent & Returned \\
\hline A & 6 & 0 & A & 6 & 9 \\
\hline B & 5 & 10 & B & 2 & 1 \\
\hline $\mathrm{C}$ & 0 & 0 & $\mathrm{C}$ & 0 & 0 \\
\hline D & 5 & 0 & D & 6 & 3 \\
\hline E & 4 & 0 & $\mathrm{E}$ & 10 & 12 \\
\hline F & 4 & 4 & $\mathrm{~F}$ & 4 & 5 \\
\hline G & 8 & 16 & G & 2 & 1 \\
\hline $\mathrm{H}$ & 0 & 0 & $\mathrm{H}$ & 10 & 5 \\
\hline I & 10 & 0 & I & 5 & 15 \\
\hline Averages: & $\$ 4.67$ & $\$ 4.29$ & Averages: & $\$ 5.00$ & $\$ 6.38$ \\
\hline \multicolumn{3}{|l|}{ Session III } & \multicolumn{3}{|c|}{ Session IV } \\
\hline A & 0 & 0 & A & 10 & 0 \\
\hline B & 5 & 8 & B & 5 & 8 \\
\hline $\mathrm{C}$ & 5 & 10 & C & 0 & 0 \\
\hline D & 1 & 1 & $\mathrm{D}$ & 5 & 10 \\
\hline E & 4 & 5 & $\mathrm{E}$ & 3 & 0 \\
\hline $\mathrm{F}$ & 4 & 0 & $\mathrm{~F}$ & 10 & 21 \\
\hline G & 5 & 8 & G & 5 & 15 \\
\hline $\mathrm{H}$ & 7 & 7 & $\mathrm{H}$ & 6 & 5 \\
\hline I & 10 & 15 & I & 10 & 8 \\
\hline Averages: & $\$ 4.56$ & $\$ 6.75$ & Averages: & $\$ 6.00$ & $\$ 8.38$ \\
\hline \multicolumn{6}{|l|}{ Session V } \\
\hline A & 5 & 0 & & & \\
\hline B & 5 & 3 & & & \\
\hline $\mathrm{C}$ & 5 & 10 & & & \\
\hline D & 10 & 13 & & & \\
\hline E & 10 & 15 & & & \\
\hline $\mathrm{F}$ & $*$ & $*$ & & & \\
\hline G & 6 & 9 & & & \\
\hline $\mathrm{H}$ & 10 & 20 & & & \\
\hline I & 5 & 5 & & & \\
\hline Averages: & $\$ 7.00$ & $\$ 9.38$ & & & \\
\hline
\end{tabular}

Investor averages include $\$ 0$ amounts invested. Steward averages exclude observations where $\$ 0$ was received.

* Missing data. 
sessions for both groups, although the amount invested appears to be increasing in Group 1 but decreasing in Group 2. With respect to the amount returned, the average amounts returned for Sessions I and II are $\$ 4.29$ and $\$ 5.25$, respectively. For Group 2, the average amounts returned are $\$ 6.28$ and $\$ 2.71$, respectively. Again, one-sided Wilcoxon rank-sum tests indicate that there is no statistical difference between the amounts returned for the two sessions for both groups, although the amount returned appears to be increasing in Group 1 but decreasing in Group 2.

$\mathrm{H} 2$ predicted that stewards who receive nonzero amounts will return nonzero amounts. Therefore, in order to test $\mathrm{H} 2$ we removed observations where the stewards received $\$ 0$. In Group 1, the average amounts returned by stewards for those who received nonzero amounts increased monotonically from $\$ 4.29$ in Session I (no history) to $\$ 9.38$ in Session V (financial history), with an overall average of $\$ 7.04$ (Table 1). Excluding cases where stewards received $\$ 0$, one-sided Wilcoxon rank-sum tests for amounts that are converted into percentages of the maximum amount that could be returned yielded one-sided $p$-values $<.023$ for all sessions other than Session I. In Session I, the Wilcoxon rank-sum test yielded a one-sided $p$ value of .174 . The latter results may be attributed to the relatively large number of Stewards who received positive amounts but returned $\$ 0$ in Session I. In Group 2, however, the average amounts returned by stewards decreased initially from $\$ 5.25$ in Session I (no history) to $\$ 1.29$ in Session III before rising to $\$ 3.76$ in Session V, for an overall average of $\$ 3.50$ (Table 2). Excluding cases where stewards received $\$ 0$, one-sided Wilcoxon rank-sum tests for amounts that are converted into percentages of the maximum amount that could be returned yielded one-sided $p$-values $<.10$ for Sessions I, IV, and V. For Sessions II and III, however, the one-sided $p$-value is .10 and .37 , respectively. Overall, the results from Group 1 and Group 2 support H2, but the Group 2 results are weaker. Again, as a direct comparison with Berg et al. (1995), we also compare the percentages of the maximum amount that could be returned between Session I (i.e., the generation without financial history) and Session II (i.e., the immediate generation that observes financial history). For Group 1, the average percentage returned for Sessions I and II are 0.238 and 0.366 , respectively. For Group 2 , the average percentage returned for Sessions I and II are 0.275 and 0.371 , respectively. One-sided Wilcoxon rank-sum tests for both groups indicate that there is no statistical difference between the percentage of the amounts sent across the two sessions, although the percentage invested appears to be increasing in both groups. 
Table 2. Group 2 Amounts Sent and Returned, by Experimental Session.

\begin{tabular}{|c|c|c|c|c|c|}
\hline \multicolumn{3}{|l|}{ Session I } & \multicolumn{3}{|c|}{ Session II } \\
\hline Subject pair & Sent & Returned & Subject pair & Sent & Returned \\
\hline A & 1 & 1 & A & 8 & 10 \\
\hline B & 5 & 8 & B & 0 & 0 \\
\hline $\mathrm{C}$ & 7 & 1 & $\mathrm{C}$ & 2 & 0 \\
\hline D & 8 & 0 & D & 1 & 1 \\
\hline E & 4 & 3 & $\mathrm{E}$ & 5 & 0 \\
\hline $\mathrm{F}$ & 10 & 18 & $\mathrm{~F}$ & 0 & 0 \\
\hline G & 5 & 10 & G & 5 & 7 \\
\hline $\mathrm{H}$ & 0 & 0 & $\mathrm{H}$ & 1 & 0 \\
\hline I & 7 & 1 & I & 2 & 1 \\
\hline Averages: & $\$ 5.22$ & $\$ 5.25$ & Averages: & $\$ 2.67$ & $\$ 2.71$ \\
\hline \multicolumn{3}{|l|}{ Session III } & \multicolumn{3}{|c|}{ Session IV } \\
\hline A & 6 & 0 & A & 0 & 0 \\
\hline B & 3 & 4 & B & 9 & 10 \\
\hline $\mathrm{C}$ & 1 & 0 & C & 3 & 3 \\
\hline D & 2 & 0 & D & 0 & 0 \\
\hline E & 7 & 5 & $\mathrm{E}$ & 0 & 0 \\
\hline $\mathrm{F}$ & 0 & 0 & $\mathrm{~F}$ & 3 & 5 \\
\hline G & 6 & 0 & G & 5 & 5 \\
\hline $\mathrm{H}$ & 0 & 0 & $\mathrm{H}$ & 0 & 0 \\
\hline I & 2 & 0 & I & 3 & 0 \\
\hline Averages: & $\$ 3.00$ & $\$ 1.29$ & Averages: & $\$ 2.56$ & $\$ 4.60$ \\
\hline \multicolumn{6}{|l|}{ Session V } \\
\hline A & 1 & 1 & & & \\
\hline B & 10 & 10 & & & \\
\hline $\mathrm{C}$ & 0 & 0 & & & \\
\hline D & 6 & 0 & & & \\
\hline E & 6 & 0 & & & \\
\hline $\mathrm{F}$ & 8 & 8 & & & \\
\hline G & 0 & 0 & & & \\
\hline $\mathrm{H}$ & 3 & 3 & & & \\
\hline I & 3 & 4 & & & \\
\hline Averages: & $\$ 4.11$ & $\$ 3.71$ & & & \\
\hline
\end{tabular}

Investor averages include $\$ 0$ amounts invested. Steward averages exclude observations where $\$ 0$ was received. 
Although we did not predict the effect that financial history might have on the amounts sent and returned, in Group 1 we did observe a successive increase in the amounts sent by investors in three of the four financial history conditions, and a successive increase in the amounts returned by Stewards in all four financial history conditions. These Group 1 results suggest that financial history can yield socially beneficial outcomes. In Group 2, however, both the amounts sent and the amounts returned are largest in Session 1 (No Financial History); the amounts sent and returned actually decreased in Sessions II and III, and only partly rebounded in Sessions IV and V. Overall, these results provide mixed evidence that financial histories can foster socially beneficial outcomes in the Investment Game setting.

\section{Influence of Financial History on Entropy}

\section{Investor Behavior}

H3 predicted that the introduction of financial history would reduce the entropy of amounts sent by investors. Panel A of Table 3 and Panel A of Table 4 list the number of investors, tabulated by amount invested and experimental session, for Group 1 and Group 2, respectively. Figs. 1(a) and (b) display histograms of the amounts invested in each of the experimental sessions for Group 1 and Group 2, respectively. A visual inspection of Fig. 1(a) indicates that the introduction of a financial history reduced the variance in the Group 1 amounts invested across the experimental sessions, where the amounts in Session I are more dispersed than in Session V. More formally, Entropy session $\mathrm{I}=2.503$ and Entropy session $\mathrm{v}$ $=1.406$, indicating a reduction in entropy of 1.098. Fig. 2(a) displays the Group 1 bootstrapping results for the amounts invested. Based on the bootstrapped distribution, the observed 1.098 reduction in entropy for the amounts invested is statistically significant $(p<.01$, one-tailed). These Group 1 results support $\mathrm{H3}$, and are consistent with our entropy analysis of the Berg et al. (1995) data. Again, as a direct comparison with Berg et al. (1995), we also compared the reduction in entropy for the amounts invested between Sessions I and II. We have Entropy session I $_{\text {I }}$ 2.503 and Entropy session II $_{\text {II }}=2.503$, indicating a reduction in entropy of 0 . Bootstrapping showed that this entropy reduction of 0 is statistically insignificant. Thus, while Berg et al. (1995) shows that one generation of financial history is able to reduce entropy, our results indicate that one generation of financial history may not be enough. 
Table 3. Number of Group 1 Investors, Listed by Experimental Session and Amounts Sent and Returned.

\begin{tabular}{lccccc}
\hline \multicolumn{6}{l}{ Panel A. Number of Group 1 investors, by experimental session and amount sent. } \\
\hline Amounts sent & Session I & Session II & Session III & Session IV & Session V \\
\hline 0 & 2 & 1 & 1 & 1 & 0 \\
1 & 0 & 0 & 1 & 0 & 0 \\
2 & 0 & 2 & 0 & 0 & 0 \\
3 & 0 & 0 & 0 & 1 & 0 \\
4 & 2 & 1 & 2 & 0 & 0 \\
5 & 2 & 1 & 3 & 3 & 4 \\
6 & 1 & 2 & 0 & 1 & 1 \\
7 & 0 & 0 & 1 & 0 & 0 \\
8 & 1 & 0 & 0 & 0 & 0 \\
9 & 0 & 0 & 0 & 0 & 0 \\
10 & 1 & 2 & 1 & 3 & 3 \\
Entropy & 2.503 & 2.503 & 2.419 & 2.113 & 1.406 \\
\hline
\end{tabular}

Panel B. Number of Group 1 stewards, by experimental session and amounts returned in deciles of percentage of amounts received from investors. Observations where investors sent $\$ 0$ are excluded.

\begin{tabular}{lccccc}
\hline Deciles of percentage & Session I & Session II & Session III & Session IV & Session V \\
\hline 0 & 4 & 0 & 1 & 2 & 1 \\
$(0 \%, 10 \%]$ & 0 & 0 & 0 & 0 & 0 \\
$(10 \%, 20 \%]$ & 0 & 4 & 0 & 0 & 1 \\
$(20 \%, 30 \%]$ & 0 & 0 & 0 & 2 & 0 \\
$(30 \%, 40 \%]$ & 1 & 1 & 2 & 0 & 1 \\
$(40 \%, 50 \%]$ & 0 & 2 & 2 & 0 & 3 \\
$(50 \%, 60 \%]$ & 0 & 0 & 2 & 1 & 0 \\
$(60 \%, 70 \%]$ & 2 & 0 & 1 & 2 & 2 \\
$(70 \%, 80 \%]$ & 0 & 0 & 0 & 0 & 0 \\
$(80 \%, 90 \%]$ & 0 & 0 & 0 & 0 & 0 \\
$(90 \%, 100 \%]$ & 0 & 1 & 0 & 1 & 0 \\
Entropy & 1.379 & 1.750 & 2.250 & 2.250 & 2.156 \\
\hline
\end{tabular}

Similarly, a visual inspection of Fig. 1(b) indicates that the introduction of a financial history reduced the variance in the Group 2 amounts invested across the experimental sessions, where the amounts in Session I are more dispersed than in Session V. More formally, Entropy session $I_{I}=2.725$ and Entropy $_{\text {session } v}=2.503$, indicating a reduction in entropy of 0.222 . Fig. 2(b) displays the Group 2 bootstrapping results for the amounts invested. The bootstrapped distribution indicates that the observed 0.222 reduction in entropy for the Group 2 amounts invested is not statistically significant 
Table 4. Number of Group 2 Investors, Listed by Experimental Session and Amounts Sent and Returned.

\begin{tabular}{llllll}
\hline \multicolumn{6}{l}{ Panel A. Number of Group 2 investors, by experimental session and amount sent. } \\
\hline Amounts Sent & Session I & Session II & Session III & Session IV & Session V \\
\hline 0 & 3 & 2 & 2 & 4 & 2 \\
1 & 2 & 2 & 1 & 0 & 1 \\
2 & 0 & 2 & 2 & 0 & 0 \\
3 & 1 & 0 & 1 & 3 & 2 \\
4 & 3 & 0 & 0 & 0 & 0 \\
5 & 2 & 2 & 0 & 1 & 0 \\
6 & 3 & 0 & 2 & 0 & 2 \\
7 & 1 & 0 & 1 & 0 & 0 \\
8 & 1 & 1 & 0 & 0 & 1 \\
9 & 0 & 0 & 0 & 1 & 0 \\
10 & 1 & 0 & 0 & 0 & 1 \\
Entropy & 2.725 & 2.281 & 2.503 & 1.753 & 2.503 \\
\hline
\end{tabular}

Panel B. Number of Group 2 stewards, by experimental session and amounts returned in deciles of percentage of amounts received from investors. Observations where investors sent $\$ 0$ are excluded.

\begin{tabular}{llllll}
\hline Deciles of Percentage & Session I & Session II & Session III & Session IV & Session V \\
\hline 0 & 1 & 3 & 5 & 1 & 2 \\
$(0 \%, 10 \%]$ & 2 & 0 & 0 & 0 & 0 \\
$(10 \%, 20 \%]$ & 0 & 1 & 0 & 0 & 0 \\
$(20 \%, 30 \%]$ & 1 & 0 & 1 & 0 & 0 \\
$(30 \%, 40 \%]$ & 1 & 1 & 0 & 3 & 4 \\
$(40 \%, 50 \%]$ & 0 & 2 & 1 & 0 & 1 \\
$(50 \%, 60 \%]$ & 2 & 0 & 0 & 1 & 0 \\
$(60 \%, 70 \%]$ & 1 & 0 & 0 & 0 & 0 \\
$(70 \%, 80 \%]$ & 0 & 0 & 0 & 0 & 0 \\
$(80 \%, 90 \%]$ & 0 & 0 & 0 & 0 & 0 \\
$(90 \%, 100 \%]$ & 0 & 0 & 0 & 0 & 0 \\
Entropy & 2.5 & 1.842 & 1.149 & 1.371 & 1.379 \\
\hline
\end{tabular}

at conventional significance levels. In sum, the group 1 results are consistent with $\mathrm{H} 3$ and our entropy analysis of the Berg et al. (1995) investor amounts, but the Group 2 results are mixed and inconclusive. ${ }^{5}$ Again, as a direct comparison with Berg et al. (1995), we also compared the reduction in entropy for the amounts invested between Sessions I and II. We have Entropy $_{\text {session I }}=2.725$ and Entropy session II $_{\text {II }}=2.281$, indicating a reduction in entropy of 0.444 . Bootstrapping showed that this entropy reduction of 0.444 is not significant at conventional levels. 
(a)
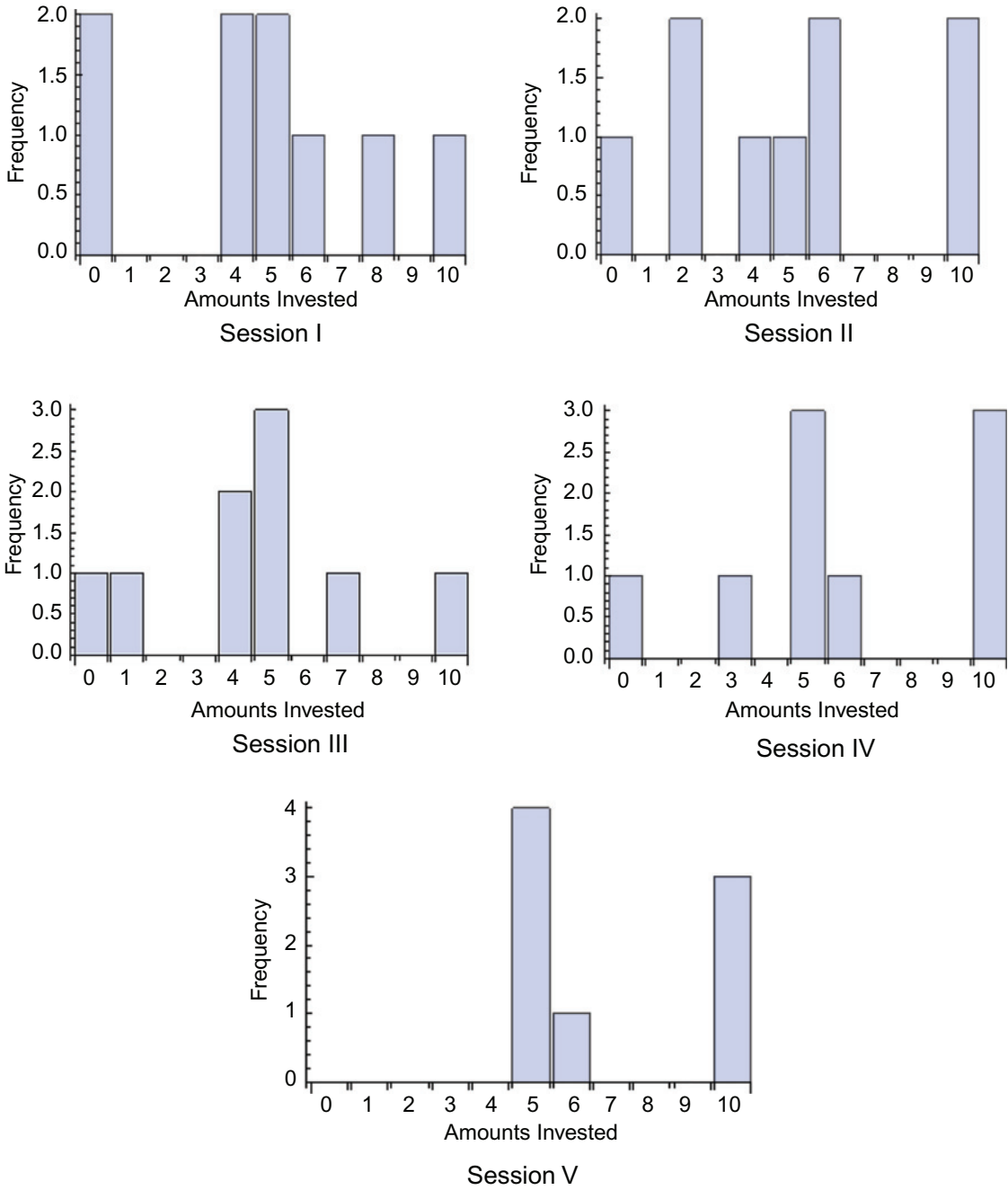

Fig. 1. Amounts Invested in Each of the Five Sessions: (a) Group 1 and (b) Group 2. 
(b)

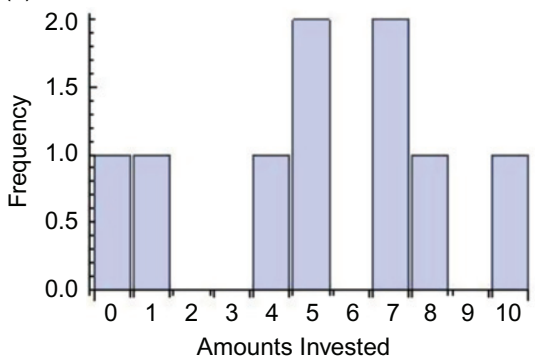

Session I

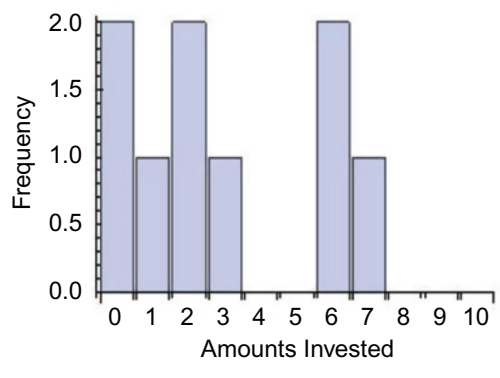

Session III

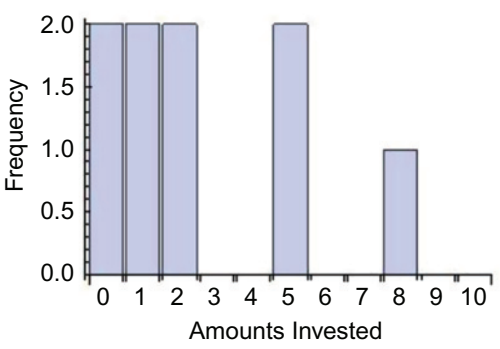

Session II

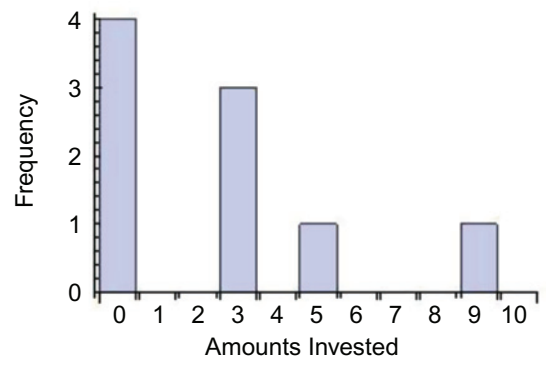

Session IV

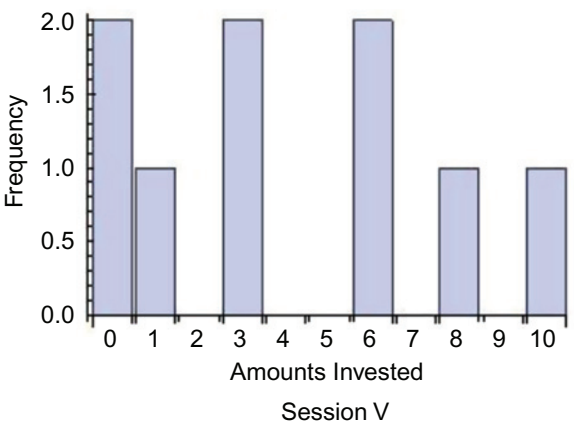

Fig. 1. (Continued)

\section{Steward Behavior}

$\mathrm{H} 4$ predicted that the introduction of financial history would reduce the entropy of amounts returned by stewards. Since the maximum amounts returned by stewards were constrained by the tripled amounts sent by 

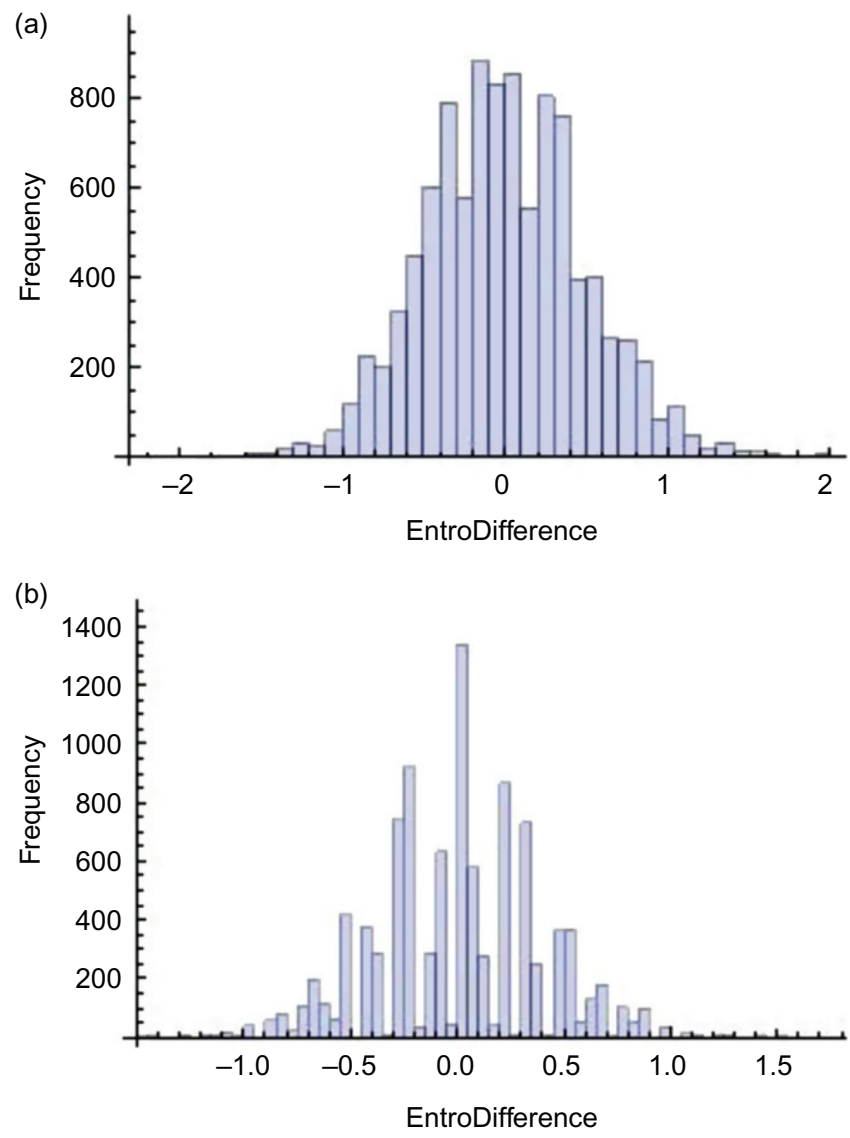

Fig. 2. Bootstrapped Distribution for Amounts Invested between Sessions I and V: (a) Group 1 and (b) Group 2.

investors, we analyzed the entropy in the distributions of the amounts returned by Stewards, converted into deciles of percentage of amounts received from Investors. Panel B of Table 3 and Panel B of Table 4 list the number of stewards who returned, by deciles of percentages of amounts received from investors and experimental session, for Group 1 and Group 2, respectively. For Group 1, the average amounts returned by stewards as a percentage of amounts received from Sessions I to $\mathrm{V}$ are $23.8 \%, 36.6 \%$, $41.45 \%, 43.1 \%$, and $41.25 \%$, respectively. For Group 2, the average amounts returned by stewards as a percentage of amounts received from 

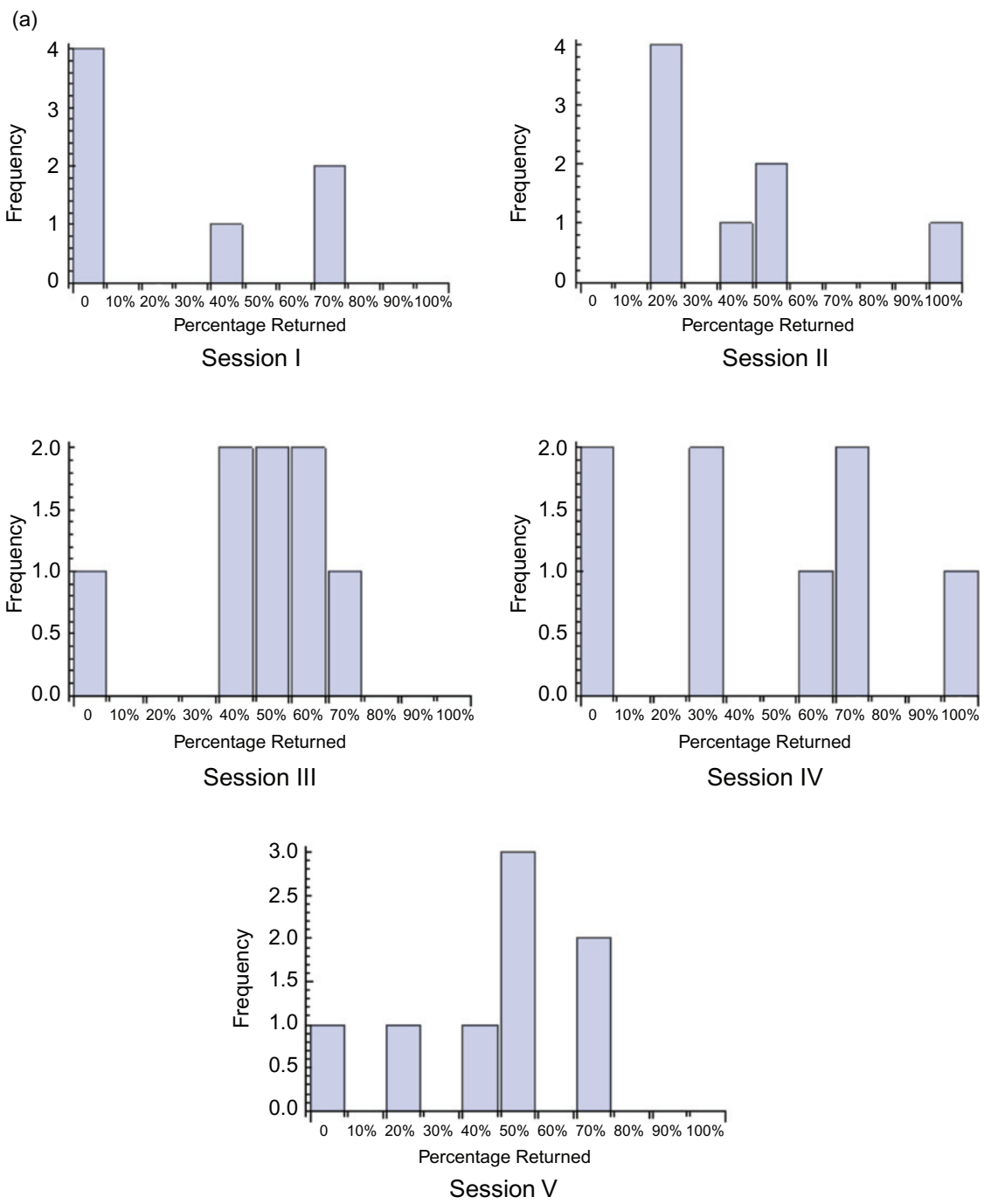

Fig. 3. Amounts Returned in Each of the Five Sessions, in Deciles of the Percentage of Amounts Received: (a) Group 1 and (b) Group 2. 
(b)
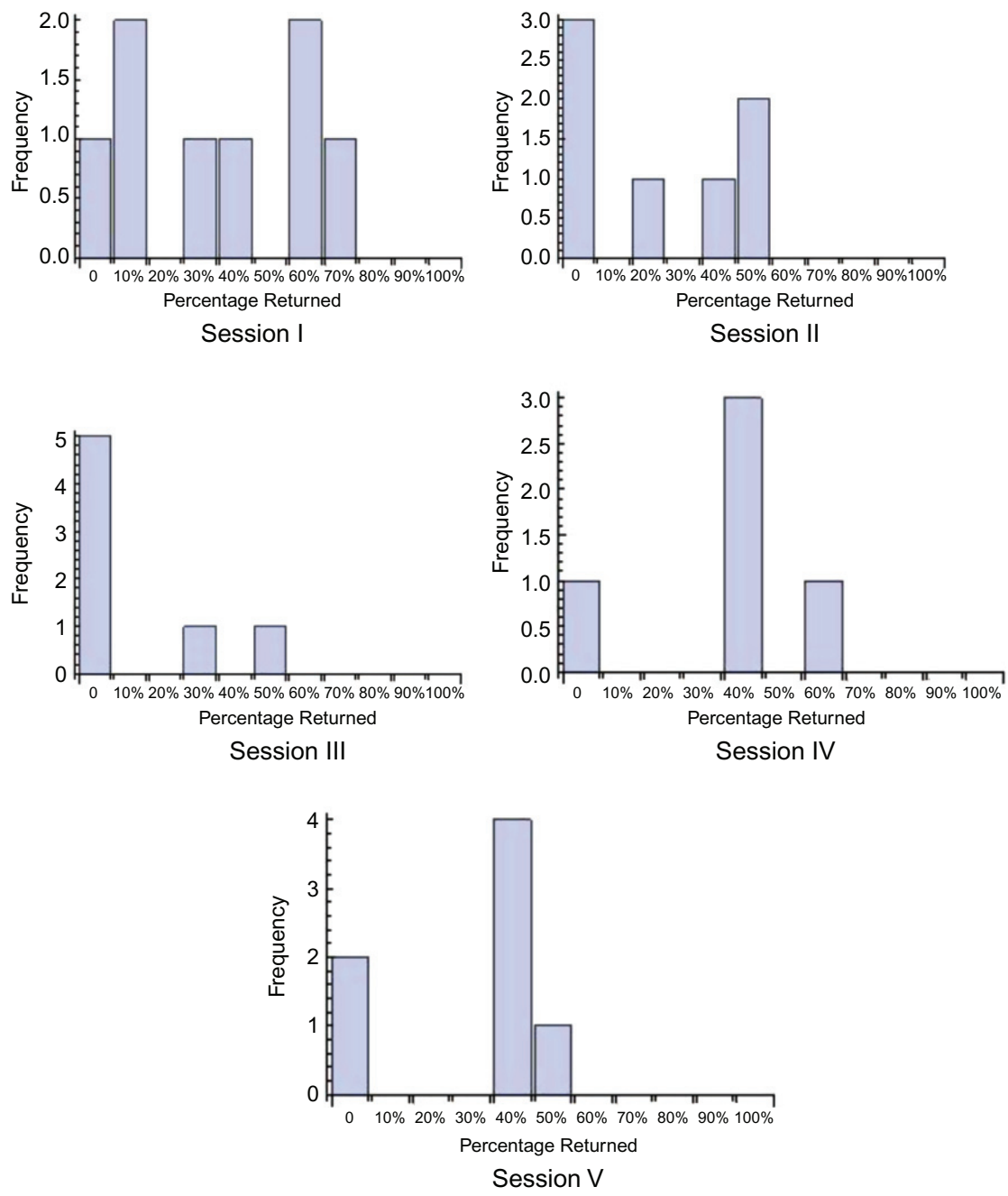

Fig. 3. (Continued)

Sessions I to $\mathrm{V}$ are $30.98 \%, 19.76 \%, 9.75 \%, 31.85 \%$, and $25.39 \%$, respectively. Fig. 3(a) (Fig. 3(b)) shows histograms of the Group 1 (Group 2) amounts returned in deciles of amounts received, for each of the five sessions. The Group 1 Steward distributions in Fig. 3(a) do not reveal a trend 
toward less variance across the five sessions. In contrast, the Group 2 Steward distributions in Fig. 3(b) reveal a trend toward less variance, though not in a socially beneficial direction, as the average percentage of amounts returned by stewards generally decreases across sessions. ${ }^{6}$

More formally, for Group 1, Entropy session I $_{\text {I }} 1.379$ and Entropy ${ }_{\text {session }}$ $\mathrm{v}=2.156$, indicating a trend toward more entropy (less order). We again used a bootstrapping technique to determine whether the observed Entropy difference of 0.777 is statistically significant. The null hypothesis for this test is that the returned amounts are chosen randomly. Fig. 4(a) displays the bootstrapping results for Group 1. Based on this bootstrapped distribution, Session V has a significantly higher entropy compared to Session I (one-tailed $p<.05$ ). ${ }^{7}$ This result is contrary to H4 and our entropy analysis of the Berg et al. (1995) Steward distributions. We conjecture that our result may be attributed to how Group 1 Session I Stewards exhibited more frequent zero amounts returned. The subsequent greater dispersion in the amounts returned by Group 1 Stewards in Sessions II-V resulted in higher entropy, but also indicates that a financial history yielded more trustworthy stewards. Consistent with this interpretation, Berg et al. (1995, p. 132) speculated (citing Coleman, 1990) that the provision of a financial history might enable Stewards to more easily identify with other investment game participants, and thus trigger internalized social norms of trustworthiness. As a direct comparison with Berg et al. (1995), we also compared the reduction in entropy for the amounts invested between Sessions I and II. We have Entropy session I $_{\text {I }}=1.379$ and Entropy $_{\text {session II }}=$ 1.75 , indicating an increase in entropy of 0.371 . Bootstrapping showed that this entropy reduction of 0.371 is not significant at conventional levels.

In contrast, for Group 2, Entropy $\mathrm{session} \mathrm{I}_{\mathrm{I}}=2.500$ and Entropy $\mathrm{session} \mathrm{v}=$ 1.379 , indicating a trend toward less entropy (more order). We again used a bootstrapping technique to determine whether the observed Entropy difference of 1.121 is statistically significant. The null hypothesis for this test is that the returned amounts are chosen randomly. Fig. 4(b) displays the bootstrapping results for Group 2. Based on this bootstrapped distribution, Session V has a significantly lower entropy than Session I $(p<.01$, onetailed). ${ }^{8}$ These Group 2 results are consistent with $\mathrm{H} 4$ and our entropy analysis of the Berg et al. (1995) Steward distributions. In addition, when combined with the observation that the percentage of amounts returned by steward decreased as more financial history was revealed, it appears that the provision of a financial history enabled stewards to more easily identify whether other investment game participants were trustworthy or not. 

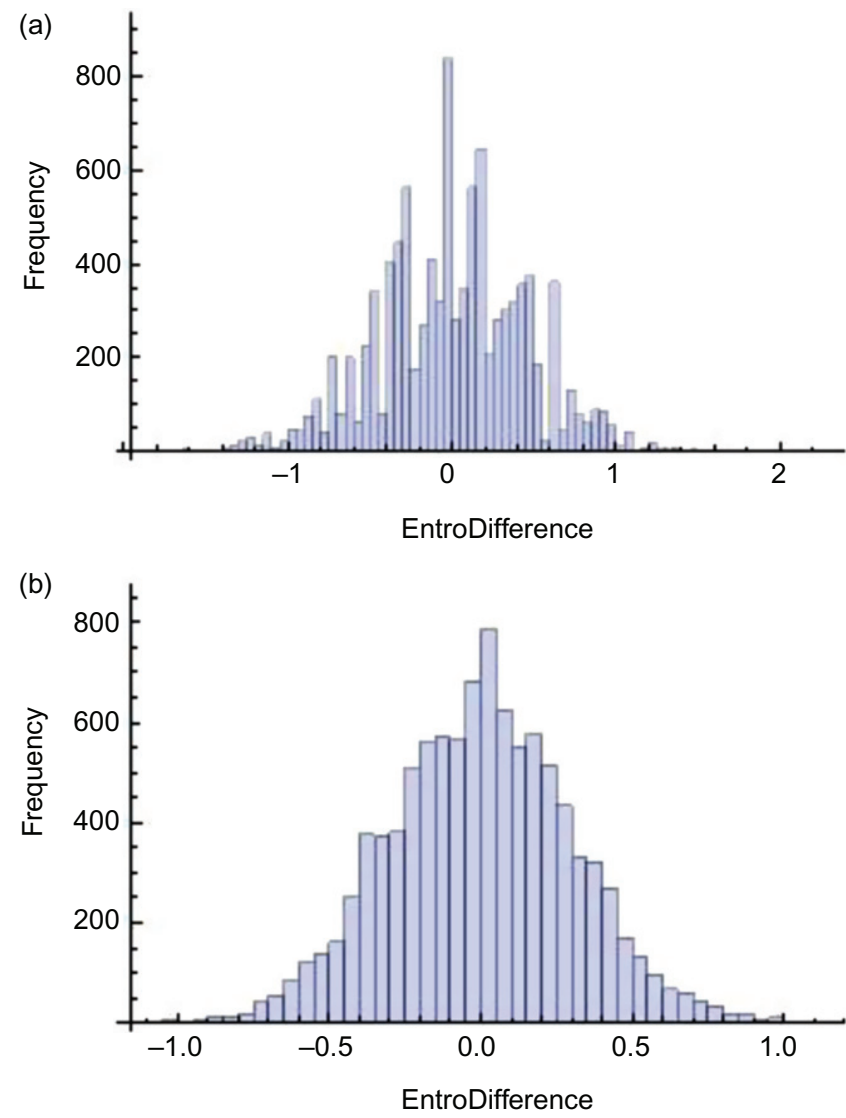

Fig. 4. Bootstrapped Distribution for Percentage Amounts Returned between Sessions I and V: (a) Group 1 and (b) Group 2.

Specifically, the financial history based on Group 2 Session I may have led Group 2 Session II stewards to infer a social norm whereby most participants are not expected to be trustworthy, and consequently more of them returned zero even when they received positive amounts from investors. Overall, however, the Group 1 and Group 2 results provide mixed support for H4's prediction that financial history would reduce the entropy in the amounts returned by Stewards. ${ }^{9}$ As a direct comparison with Berg et al. (1995), we also compared the reduction in entropy for the amounts invested between Sessions I and II. We have Entropy session I $_{\text {I }}=2.500$ and 
Entropy $_{\text {session }}$ II $=1.842$, indicating an increase in entropy of 0.658 . Bootstrapping showed that this entropy reduction of 0.658 is marginally significant $(p<.1$, one-tailed).

\section{Joint Test of Investor/Steward Behavior}

We now examine the joint densities of Investor and Steward behavior to test whether the observed clustering is statistically significant, as predicted by $\mathrm{H} 5$. Since each session has the same sample size of 9 , the effect of sample size on the entropy metric does not arise in our setting. The entropy formula is as follows:

$$
-\sum_{i} \sum_{j} \frac{f_{i}, j}{N} \log _{2} \frac{f_{i}, j}{N}
$$

where $f_{i j}$ denotes the frequency in category " $i, j$." For example, "3,2" denotes 3 dollars invested and 2 returned by the steward and $N$ represents the number of sample observations. Under this metric for Group 1, Entropy $_{\text {session I }}=2.948$ and Entropy session $\mathrm{v}=2.750$. Our bootstrapped distribution indicates that the 0.198 reduction in entropy in the Group I joint Investor/Steward distributions from Session I to $\mathrm{V}$ is not significant (onetailed $p>.4$ ). The results for Group 2 and a combination of Group 1 and Group 2 are qualitatively similar. As a direct comparison with Berg et al. (1995), we also compared the reduction in entropy for the amounts invested between our Sessions I and II. Again, the results are not statistically significant. Altogether, these results do not support H5, and are contrary to the marginally significant reduction in entropy we observed from Session I to Session II in the Berg et al. (1995) joint distributions (Table 5; Fig. 5).

\section{GENERAL DISCUSSION}

We used the Berg et al. (1995) data to show that a report summarizing the financial transactions of a previous experimental session significantly reduced entropy in the amounts sent by Investors and returned by Stewards, and marginally reduced the entropy in the joint distribution of amounts invested and returned. We then sought to replicate these Berg et al. (1995) findings as well as extend their study by investigating whether financial histories will further reduce entropy over subsequent generations. More specifically, we investigated whether the provision of financial 
Table 5. Number of Investors in Group 1 and Group 2 Combined, Listed by Experimental Session and Amounts Sent and Returned.

\begin{tabular}{llllll}
\hline \multicolumn{5}{l}{ Panel A. Number of investors in both groups, by experimental session and amount sent. } \\
\hline Amounts Sent & Session I & Session II & Session III & Session IV & Session V \\
\hline 0 & 1 & 3 & 3 & 5 & 2 \\
1 & 1 & 2 & 2 & 0 & 1 \\
2 & 0 & 4 & 2 & 0 & 0 \\
3 & 0 & 0 & 1 & 4 & 2 \\
4 & 1 & 1 & 2 & 0 & 0 \\
5 & 2 & 3 & 3 & 4 & 4 \\
6 & 0 & 2 & 2 & 1 & 3 \\
7 & 2 & 0 & 2 & 0 & 0 \\
8 & 1 & 1 & 0 & 0 & 1 \\
9 & 0 & 0 & 0 & 1 & 0 \\
10 & 1 & 2 & 1 & 3 & 4 \\
Entropy & 3.01307 & 2.86383 & 3.08605 & 2.3719 & 2.63129
\end{tabular}

Panel B. Number of stewards in Group 1 and Group 2 combined, listed by experimental session and amounts returned in deciles of percentage of amounts received from investors. Observations where investors sent $\$ 0$ are excluded.

\begin{tabular}{llllll}
\hline Deciles of Percentage & Session I & Session II & Session III & Session IV & Session V \\
\hline 0 & 5 & 3 & 6 & 3 & 3 \\
$(0 \%, 10 \%]$ & 2 & 0 & 0 & 0 & 0 \\
$(10 \%, 20 \%]$ & 0 & 5 & 0 & 0 & 1 \\
$(20 \%, 30 \%]$ & 1 & 0 & 1 & 2 & 0 \\
$(30 \%, 40 \%]$ & 2 & 2 & 2 & 3 & 5 \\
$(40 \%, 50 \%]$ & 0 & 4 & 3 & 0 & 4 \\
$(50 \%, 60 \%]$ & 2 & 0 & 2 & 2 & 0 \\
$(60 \%, 70 \%]$ & 3 & 0 & 1 & 2 & 2 \\
$(70 \%, 80 \%]$ & 0 & 0 & 0 & 0 & 0 \\
$(80 \%, 90 \%]$ & 0 & 0 & 0 & 0 & 0 \\
$(90 \%, 100 \%]$ & 0 & 1 & 0 & 1 & 0 \\
Entropy & 2.41592 & 2.14926 & 2.28925 & 2.50738 & 2.14926 \\
\hline
\end{tabular}

transaction history from preceding generations will enable successive generations of a laboratory society to increasingly organize themselves over time. We operationally defined an increase in organization as a reduction in entropy of the distributions of amounts invested and returned in an investment game. To test the predictive power of our main hypothesis that financial histories over successive generations will enable the emergence of increasing societal order, we gathered new data from two groups (Group 1 and Group 2) over five societal generations. 

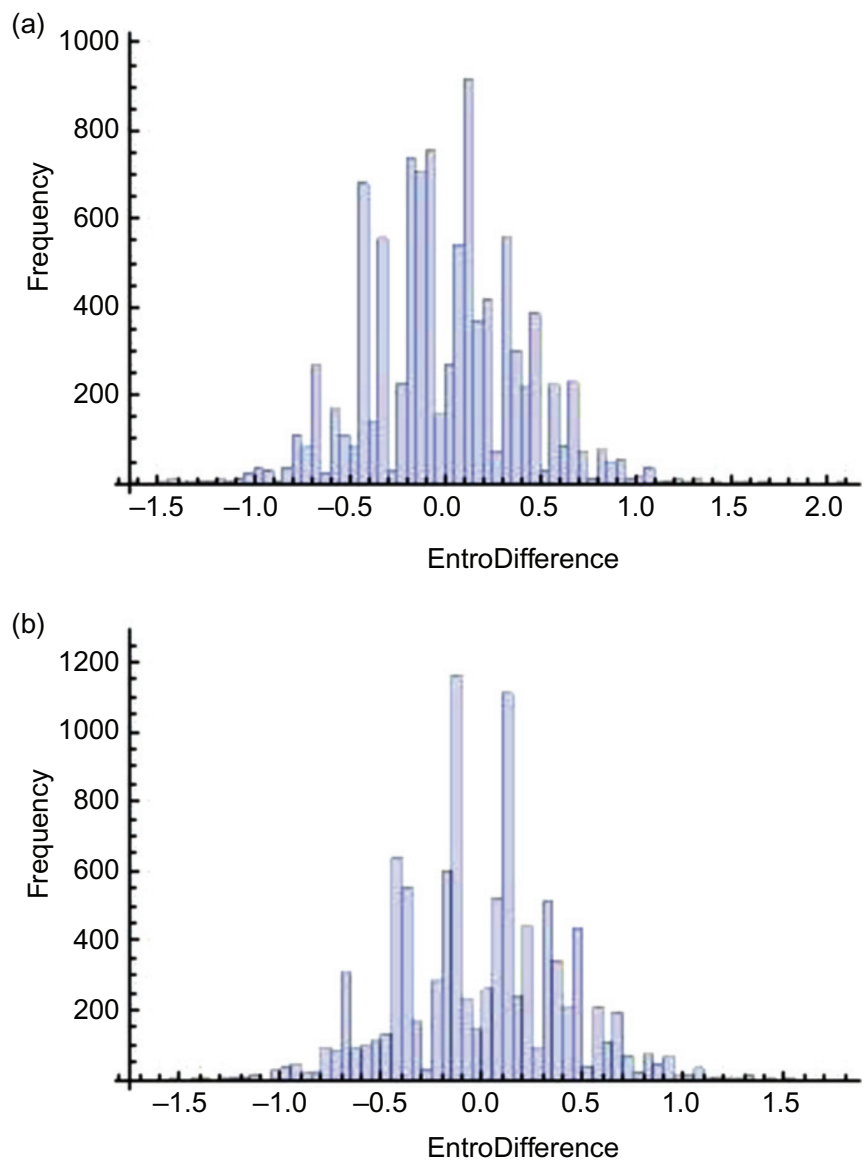

Fig. 5. Bootstrapped Distribution for the Joint Behavior between Sessions I and V: (a) Group 1 and (b) Group 2.

If we assume that all agents are myopically self-interested and believe that all other agents are similarly self-interested, then each Investor and Steward should "take the money and run," leaving no role for financial history in the evolution of society. In order for financial history to play a role in our experimental setting, the assumption of myopic self-interest needs to be relaxed. For example, if each Investor is myopically self-interested but believes that his or her partner might not be, then a financial history of past Investor/Steward behavior can tell Investors something about the 
likely amount returned for each amount invested. Thus, financial histories might influence the amounts invested, and if Stewards are not myopically self-interested, financial histories might also give Stewards a basis to infer and mimic expected or acceptable behavior.

Consistent with the prior investment game literature and our $\mathrm{H} 1$, our bootstrap analyses indicate that the distributions of amounts sent by Investors in all five sessions for both Group 1 and Group 2 differed significantly from zero. Similarly, the distributions of amounts returned by Stewards generally supported our $\mathrm{H} 2$ but the results were more mixed. Specifically, the distributions of amounts returned by Stewards were significantly greater than zero for four of five Group 1 Sessions and three of five Group 2 sessions.

Overall, however, the pattern of results across our study and the Berg et al. (1995) study indicates that the impact of financial history on entropy reduction is not as robust as initially thought. More specifically, consistent with our $\mathrm{H} 3$, our bootstrap analyses indicate that financial history generally reduced the entropy in the amounts sent by Investors across the five sessions, with stronger results for Group 1 than for Group 2. In contrast, we found mixed support for a reduction in entropy in the amounts returned by Stewards (H4). Specifically, the entropy in the Group 2 Session V amounts returned by Stewards was significantly lower than the entropy in the Group 2 Session I amounts, as predicted by our H4, but the entropy in the Group 1 Session V amounts returned by Stewards was higher rather than lower than the entropy in the Group 1 Session I amounts. Finally, our analyses did not support our H5 prediction that financial history would reduce entropy in the joint Investor/Steward distributions. The combined entropy results for $\mathrm{H} 3-\mathrm{H} 5$ yielded a similar pattern. Clearly, more research is needed to document the potential mediating effects of financial history across a variety of conditions. Below, we discuss several opportunities for future research.

First, along with Berg et al. (1995), we conjectured that the provision of a financial history might enable stewards to more easily identify whether other Investment Game stewards are trustworthy. This suggests that the impact of financial history may depend on initial conditions and is path dependent. For example, if financial histories indicate that past stewards tended to be trustworthy, current and future stewards might internalize social norms of trustworthiness and consequently tend to act in a more trustworthy manner. Likewise, current and future investors might internalize social norms of trusting behavior and consequently be willing to invest more. The opposite Investor and Steward patterns may emerge if financial 
histories indicate that stewards tend to return zero or very low amounts. A larger set of experiments would be required to formally test how initial conditions and other path dependencies might interact with financial histories.

Second, entropy reduction is only one of several possible social outcomes that could be mediated by financial histories. Indeed, as we observed in our data, it is possible for financial histories to yield more disperse but also more trustworthy Stewardship distributions, or instead yield less diverse but also less trustworthy Stewardship distributions. For example, an emergent increase in Stewardship trustworthiness might in turn yield more trusting Investors over subsequent generations. These iterative effects could ultimately yield greater overall social wealth, despite higher entropy in the amounts returned by Stewards. On the other hand, if Investment Game participants tend to distrust each other in the beginning, financial histories might shape participants' perceptions of other people and thereby augment their distrust. This would in turn yield lower entropy but lower total social wealth as the investors send and stewards return lower amounts. Again, a larger set of experiments would be required to examine these potential effects.

Third, variations of the Investment Game could be used to test the incremental effects of financial history when Investors and Stewards participate in multiple sessions and are allowed to communicate with one another (cf. Charness, Duh, \& Yang, 2011; Chaudhuri et al., 2009), or when social distance between the experimenter and subjects is varied (cf. Cox \& Deck, 2005; who found more positively reciprocal behavior in the Trust Game when the experimenter had personal knowledge of subjects' behavior).

Fourth, Ortmann et al. (2000) found that the amounts invested by investors in the Investment Game were robust to whether the investors completed a questionnaire to prompt their strategic reasoning about stewards' likely behavior, and whether the social history was presented in table form only or in tables plus graphs. Future research could test whether such modifications will influence the amounts returned by stewards and stewards' strategic reasoning about investor behavior. But more generally, the Johnson and Mislin (2011) meta-analysis of investment game studies found mixed results from prior studies that engaged subjects to think strategically through the various behavioral implications of each possible outcome. This suggests that the effect of conscious strategies may be highly contingent on other factors that remain to be identified and experimentally controlled.

Finally, although the reporting of financial histories can be a conscious strategy that societal agents use to structure their economic and social environments, they also can have unintended effects on organizations and 
societies, as has been found in other measurement systems (Burchell, Clubb, Hopwood, Hughes, \& Nahapiet, 1980; Cyert \& March, 1992; Thompson, 1967). While the effects of financial histories might in some circumstances be mediated by the conscious strategies of individual agents (cf. Berg et al., 1995, p. 134), financial histories also might structure the behavior of subsequent generations without necessarily requiring agents to be consciously aware of these effects (cf. Giddens, 1984). More research is needed to ascertain the extent to which the effect of financial history is mediated by conscious versus unconscious individual perceptions and decision strategies.

\section{NOTES}

1. Ortmann et al.'s (2000) study of the Investment Game reported that the amounts invested were robust to whether the Investors completed a questionnaire designed to prompt strategic reasoning, and to changes in how the social history information was presented to subjects (e.g., in tables only as in Berg et al. (1995) or in tables accompanied by graphs that showed the proportional amounts returned by stewards).

2. Specifically, when the probability of heads is 0.75 , the entropy is calculated as $-0.75 \log _{a}(0.75)-0.25 \log _{a}(0.25)$ where $a$ is the base of the logarithm. The result is approximately 0.81 when the binary logarithm (log base 2 ) is used. If we had instead calculated entropy with the natural logarithm (log base e), the result would have been approximately 0.56 . The choice of base affects the absolute value of the entropy measure but it does not affect the comparison of entropy measures when all of the measures are calculated using the same base. All of our entropy calculations use the binary logarithm.

3. Note that variance captures the same construct as entropy in a normal distribution. For non-normal distributions, however, entropy has been shown to be a better measure of uncertainty than variance. Nevertheless, we also conducted a variance analysis with qualitatively similar results.

4. Specifically, in the No History condition there are at most 32 distinct observations. This means the maximum level of entropy will be $-\log _{2}(1 / 32)=5.0$. In contrast, if there were only 28 observations, the maximum entropy would be $-\log _{2}(1 / 28)=4.8$.

5. Combining data from both Group 1 and Group 2, Entropy session $\mathrm{I}_{\mathrm{I}}=3.013$ and Entropy $_{\text {session }} \mathrm{v}=2.631$, indicating a marginally significant $(p=.10$, one-tailed $)$ reduction in entropy of 0.382 .

6. Note that while a scenario where all stewards return $100 \%$ or all stewards return $0 \%$ will generate the least amount of entropy, the former is socially beneficial whereas the latter is not.

7. Pairwise entropy differences between Group 1 Sessions II and V are not significant at conventional levels. 
8. Pairwise entropy differences between Group 1 Sessions II and V are not significant at conventional levels.

9. Combining data from both Group 1 and Group 2, Entropy session I $_{\text {I }}=2.416$ and Entropy $_{\text {session } v}=2.149$. Session V has lower entropy, but a bootstrapping test indicates that the difference of 0.267 is not significant at conventional levels.

\section{ACKNOWLEDGMENTS}

The authors thank Cary Deck (co-editor) and an anonymous reviewer for their helpful comments and suggestions, and thank John Dickhaut and Judy Rayburn for their ideas, inspiration, and encouragement in the early stages of this research. Research funding from the Merage School of Business (University of California - Irvine), the Department of Accounting at the Carlson School of Management (University of Minnesota - Twin Cities), and the University of St. Thomas Opus College of Business is gratefully acknowledged.

\section{REFERENCES}

Berg, J., Dickhaut, J., \& McCabe, K. (1995). Trust, reciprocity, and social history. Games and Economic Behavior. 10.122-142. doi:10.1006/game.1995.1027

Burchell, S., Clubb, C., Hopwood, A. G., Hughes, J., \& Nahapiet, J. (1980). The roles of accounting in organizations and society. Accounting. Organizations and Societv, 5, 5-27. doi:10.1016/0361-3682(80)90017-3

Camerer, C. F., \& Fehr, E. (2002). Measuring social norms and preferences using experimental games: A guide for social scientists. In J. Henrich. R. Boyd. S. Bowles, C. Camerer. E. Fehr \& H. Gintis (Eds.), Experimental and ethnographic evidence from 15 small-scale societies (pp. 55-95). New York, NY: Oxford University Press.

Charness, G., Du, N., \& Yang, C. (2011). Trust and trustworthiness reputations in an investment game. Games and Economic Behavior, 72, 361-375. doi:10.1016/i.geb.2010.09.002

Chaudhuri, A., Schotter, A., \& Sopher, B. (2009). Talking ourselves to efficiency: Coordination in inter-generational minimum effort games with private, almost common and common knowledge of advice. The Economic Journal, 119, 91-122. Retrieved from http://www.jstor.org/stable/20485296

Coleman, J. (1990). Foundations of social choice theory. Cambridge, MA: Harvard University Press.

Cover, T. M., \& Thomas, J. A. (1991). Elements of information theorv. New York, NY: WileyInterscience.

Cox, J. C. (2004). How to identify trust and reciprocity. Games and Economic Behavior, 46. 260-281. doi:10.1016/S0899-8256(03)00119-2 
Cox, J. C., \& Deck, C. A. (2005). On the nature of reciprocal motives. Economic Inquiry. 43(3), 623-635. doi:10.1093/ei/cbi043

Cyert, R., \& March, J. (1992). A behavioral theory of the firm (2nd ed.). Oxford: Basil Blackwell.

Dickhaut, J., \& McCabe, K. A. (1997). The behavioral foundations of stewardship accounting and a proposed program of research: What is accountability? Behavioral Research in Accounting, 9, 60-87. Retrieved from http://search.ebscohost.com/login.aspx?direct= true $\& \mathrm{db}=\mathrm{bth} \& \mathrm{AN}=9708106809 \&$ site $=$ ehost-live

Giddens, A. (1984). The constitution of society. Cambridge, MA: Polity Press.

Habermas, J. (1979). Communication and the evolution of society (T. McCarthy, Trans.). Boston, MA: Beacon Press.

Johnson, N. D., \& Mislin, A. A. (2011). Trust games: A meta-analysis. Journal of Economic Psvchologv, 32, 865-889. doi:10.1016/j.joep.2011.05.007

Kramer, R. M. (1999). Trust and distrust in organizations: Emerging perspectives, enduring questions. Annual Review of Psvchology, 50, 569-598. doi:10.1146/annurev. psych.50.1.569

Latour, B. (1993). We have never been modern. Harvard, MA: Harvard University Press.

Leydesdorff, L. (2001). A sociological theory of communication: The self-organization of the knowledge-based society. uPublish.com. Boca Raton, FL: Universal Publishers. Retrieved from http://www.upublish.com/books/leydesdorff.htm

Luhmann, N. (1986). The autopoiesis of social systems. In F. Geyer \& J. van der Zouwen (Eds.), Sociocybernetic paradoxes: Observation, control and evolution of self-steering systems (pp. 172-192). London: Sage.

Lunawat, R. (2013a). An experimental investigation of reputation effects of disclosure in an investment/trust game. Journal of Economic Behavior \& Organization, 94, 130-144. doi:10.1016/j.jebo.2013.07.018

Lunawat, R. (2013b). The role of information in building reputation in an investment/trust game. European Accounting Review, 22(3), 513-532. Retrieved from http://search.ebscohost.com/login.aspx?direct=true $\& \mathrm{db}=$ bth \&AN=89600534\&site=ehost-live

Mackowiak, B., \& Wiederholt, M. (2009). Optimal sticky prices under rational inattention. American Economic Review, 99(3), 769-803.

Ortmann, A., Fitzgerald, J., \& Boeing, C. (2000). Trust, reciprocity, and social history: A reexamination. Experimental Economics, 3, 81-100. doi:10.1023/A:1009946125005

Shannon, C. E. (1948). A mathematical theory of communication. The Bell Svstem Technical Journal, 27(July), 379-423. doi:10.1145/584091.584093

Sims, C. A. (1998). Stickiness. Carnegie-Rochester Conference Series on Public Policv, 49(1). $317-356$.

Sims, C. A. (2003). Implications of rational inattention. Journal of Monetary Economics, 50(3), 665-690. doi:10.1016/S0304-3932(03)00029-1

Sims, C. A. (2005). Rational inattention: A research agenda. Deutsche bundesbank research centre discussion paper series 1: Economic studies, 2005, 34.

Thompson, J. D. (1967). Organizations in action: Social science bases of administrative theory. New York, NY: McGraw-Hill.

Yang, M. (2015). Coordination with flexible information acquisition. Journal of Economic Theory, 158, 721-738. doi:10.1016/j.jet.2014.11.017 


\section{APPENDIX}

\section{Instructions for Room A}

You have been asked to participate in a decision-making study. I will read these instructions out loud. Please do not talk among yourselves. If you have any questions, please raise your hand. I will then answer your questions individually.

\section{Overview}

In this experiment each of you will be paired with a different participant who is in another room. You will not be told who these people are either during or after the experiment. This is Room A. Other participants are in Room B. You will notice that there are other people in the same room with you who are also participating in this experiment. You will not be paired with any of these people.

One participant in Room A will be called Monitor A, and one participant in Room B will be called Monitor B. Monitor A and Monitor B will be randomly chosen before the experiment begins. The monitors will be in charge of the envelopes as explained below. The monitors also will verify that the instructions have been followed. Monitors will be given $\$ 15$ at the end of the experiment.

Each participant in Room B who is not a monitor will be given $\$ 10$ for showing up on time and participating until the end of the experiment. Each participant in Room A will receive $\$ 10$ in an envelope. Each Room A participant will then have the opportunity to send some, all, or none of the $\$ 10$ to a participant in Room B. Each dollar sent to Room B will be tripled. For example, if a participant in Room A sends an envelope containing \$2, he or she will keep the remaining $\$ 8$ and the envelope will contain $\$ 6$ when it reaches Room B. If a participant in Room A sends an envelope containing $\$ 9$, he or she will keep the remaining $\$ 1$ and the envelope will contain $\$ 27$ when it reaches Room B. The participant in Room B will then decide how much money to send back to the participant in Room A.

(For the financial history treatment we added the following paragraph: Each of you has received a report summarizing the decisions of subjects who participated in a previous experiment. Please check the last page of the instructions to be sure you have this sheet.) 


\section{Confidentiality}

This experiment is designed so that no one, including the experimenters and monitors, will know the decisions of any individual participants in Room A or Room B. Since your decision is private, we ask that you do not tell anyone your decision either during or after the experiment.

\section{How the Experiment is Run}

Room A Participant Decisions. The experiment is conducted as follows. Ten large unmarked envelopes have been placed in a box in Room A. Each of these envelopes contains 10 one dollar bills, a smaller inner envelope, and a key in a sealed envelope marked "KEY." The inner envelope and key are both marked with the same letter of the alphabet. The Room A monitor will randomly select and hand each participant in Room A an unmarked envelope from the box. Each Room A participant will perform the following steps:

1. Privately open the unmarked envelope. The participant who opens the envelope will be the only person who knows which letter of the alphabet was in the envelope.

2. Leave the envelope marked "KEY" unopened until instructed to open it later in the experiment.

3. Privately decide how many dollar bills to put into the inner envelope, and then put those dollar bills in the inner envelope.

4. Privately pocket any remaining dollar bills and pocket the unopened envelope marked "KEY."

5. Privately put the inner envelope back inside the large unmarked envelope.

6. Raise his or her hand. When Monitor A comes by, return the unmarked envelope to the box marked "return the envelopes here."

Recording and Processing of Room A Envelopes. As soon as all Room A envelopes have been put into the return box, Monitor A will transport the box to a recorder who is sitting in the hallway. With Monitor A observing, the recorder will perform the following steps:

1. Take all unmarked envelopes out of the box.

2. Take an inner envelope out of an unmarked envelope, one at a time.

3. On a blank sheet of paper, record the letter that is printed on the envelope and the amount of money in the envelope. 
4. Triple the amount of money in the inner envelope, place the inner envelope back into the unmarked outer envelope, and place the unmarked outer envelope back in the box.

5. After all of the envelopes have been processed in this manner, the recorder will signal Monitor B to come to the recorder's desk. Once Monitor $\mathrm{B}$ has arrived, Monitor A will be asked to return to Room A.

Room B Participant Decisions. Monitor B will carry the box of envelopes to Room B. Monitor B then will randomly select and hand each participant in Room B an unmarked envelope from the box. Each Room B participant will perform the following steps:

1. Decide how many dollar bills to leave in the inner envelope.

2. Pocket any remaining dollar bills.

3. Place the inner envelope in the unmarked outer envelope.

4. Raise his or her hand. When Monitor B comes by, return the outer envelope to the box marked "return envelopes here."

5. Gather his or her belongings, receive his or her $\$ 10$ compensation for participating in the experiment, and be asked to leave the building.

Recording and Processing of Room B Envelopes. After all envelopes in Room B are returned to the box marked "return the envelopes here" and all Room B participants have been asked to leave the building, Monitor B will transport the box to the recorder in the hallway. With Monitor B observing, the recorder will perform the following steps:

1. Take all unmarked envelopes out of the box.

2. Take an inner envelope out of an unmarked envelope, one at a time.

3. Record on a blank sheet of paper the letter on the envelope and the amount of money in the envelope.

4. Place the inner envelope in the box.

5. After all of the envelopes have been processed in this manner, the recorder will then signal Monitor A to come to the recorder's desk.

Once Monitor A has arrived, Monitor B will return to Room B. When Monitor A arrives, Monitor A and the recorder will carry the box of envelopes to Room C. Room C contains locking boxes with identifying letters. The letters correspond to the letters on the inner envelopes. While the recorder observes, Monitor A will place each inner envelope in the box with the corresponding letter. All of the boxes will then be locked. The 
recorder will then return to the hallway and Monitor A will return to Room A.

Room A Participants Privately Open the Returned Envelopes. Monitor A will then point to one participant in Room A at a time to proceed to Room C. When called to go to Room C, each Room A participant will perform the following steps:

1. Gather all of his or her belongings since he or she will be asked to leave the building when done.

2. Enter Room C alone.

3. Open the envelope marked "KEY." Inside this envelope is a lettered key which will open the locked box with the corresponding letter. The inner envelope in the box is the same envelope that Room A participant started with.

4. Go to the appropriate locked box, open it, take out the envelope, and remove the money.

5. Return the empty envelope to the box.

6. Lock the box.

7. Return the key to the envelope marked "KEY."

8. Drop the envelope marked "KEY" in the box just outside the door in the hallway and be asked to leave the building.

Conclusion of Experiment. After everyone in Room A has left, the experiment is over and the two monitors will be paid $\$ 15$ for their participation.

Note about Dollar Bills. We will use e-dollars for this experiment. At the end of the experiment, your e-dollars will be converted into real dollars at a faceless teller. The conversion rate is one dollar for one e-dollar bill.

\section{Instructions for Room $B$}

You have been asked to participate in a decision-making study. I will read these instructions out loud. Please do not talk among yourselves. If you have any questions, please raise your hand. I will then answer your questions individually. 


\section{Overview}

In this experiment each of you will be paired with a different participant who is in another room. You will not be told who these people are either during or after the experiment. This is Room B. Other participants are in Room A. You will notice that there are other people in the same room with you who are also participating in this experiment. You will not be paired with any of these people.

One participant in Room A will be called Monitor A, and one participant in Room B will be called Monitor B. Monitor A and Monitor B will be randomly chosen before the experiment begins. The monitors will be in charge of the envelopes as explained below. The monitors also will verify that the instructions have been followed. Monitors will be given $\$ 15$ at the end of the experiment.

Each participant in Room B who is not a monitor will be given $\$ 10$ for showing up on time and participating until the end of the experiment. Each participant in Room A will receive $\$ 10$ in an envelope. Each Room A participant will then have the opportunity to send some, all, or none of the $\$ 10$ to a participant in Room B. Each dollar sent to Room B will be tripled. For example, if a participant in Room A sends an envelope containing \$2, he or she will keep the remaining $\$ 8$ and the envelope will contain $\$ 6$ when it reaches Room B. If a participant in Room A sends an envelope containing $\$ 9$, he or she will keep the remaining $\$ 1$ and the envelope will contain $\$ 27$ when it reaches Room B. The participant in Room B will then decide how much money to send back to the participant in Room A.

(For the financial history treatment we added the following paragraph: Each of you has received a report summarizing the decisions of subjects who participated in a previous experiment. Please check the last page of the instructions to be sure you have this sheet.)

\section{Confidentiality}

This experiment is designed so that no one, including the experimenters and monitors, will know the decisions of any individual participants in Room A or Room B. Since your decision is private, we ask that you do not tell anyone your decision either during or after the experiment.

\section{How the Experiment is Run}

Room A Participant Decisions. The experiment is conducted as follows. Twelve large unmarked envelopes have been placed in a box in Room A. Each of these envelopes contains 10 one dollar bills, a smaller inner envelope, and a key in a sealed envelope marked "KEY." The inner envelope 
and key are both marked with the same letter of the alphabet. The Room A monitor will randomly select and hand each participant in Room A an unmarked envelope from the box. Each Room A participant will perform the following steps:

1. Privately open the unmarked envelope. The participant who opens the envelope will be the only person who knows which letter of the alphabet was in the envelope.

2. Leave the envelope marked "KEY" unopened until instructed to open it later in the experiment.

3. Privately decide how many dollar bills to put into the inner envelope, and then put those dollar bills in the inner envelope.

4. Privately pocket any remaining dollar bills and pocket the unopened envelope marked "KEY."

5. Privately put the inner envelope back inside the large unmarked envelope.

6. Raise his or her hand. When Monitor A comes by, return the unmarked envelope to the box marked "return the envelopes here."

Recording and Processing of Room A Envelopes. As soon as all Room A envelopes have been put into the return box, Monitor A will transport the box to a recorder who is sitting in the hallway. With Monitor A observing, the recorder will perform the following steps:

1. Take all unmarked envelopes out of the box.

2. Take an inner envelope out of an unmarked envelope, one at a time.

3. On a blank sheet of paper, record the letter that is printed on the envelope and the amount of money in the envelope.

4. Triple the amount of money in the inner envelope, place the inner envelope back into the unmarked outer envelope, and place the unmarked outer envelope back in the box.

5. After all of the envelopes have been processed in this manner, the recorder will signal Monitor B to come to the recorder's desk. Once Monitor $\mathrm{B}$ has arrived, Monitor A will be asked to return to Room A.

Room B Participant Decisions. Monitor B will carry the box of envelopes to Room B. Monitor B then will randomly select and hand each participant in Room B an unmarked envelope from the box. Each Room B participant will perform the following steps:

1. Decide how many dollar bills to leave in the inner envelope.

2. Pocket any remaining dollar bills. 
3. Place the inner envelope in the unmarked outer envelope.

4. Raise his or her hand. When Monitor B comes by, return the outer envelope to the box marked "return envelopes here."

5. Gather his or her belongings, receive his or her $\$ 10$ compensation for participating in the experiment, and be asked to leave the building.

Recording and Processing of Room B Envelopes. After all envelopes in Room B are returned to the box marked "return the envelopes here" and all Room B participants have been asked to leave the building, Monitor B will transport the box to the recorder in the hallway. With Monitor $\mathrm{B}$ observing, the recorder will perform the following steps:

1. Take all unmarked envelopes out of the box.

2. Take an inner envelope out of an unmarked envelope, one at a time.

3. Record on a blank sheet of paper the letter on the envelope and the amount of money in the envelope.

4. Place the inner envelope in the box.

5. After all of the envelopes have been processed in this manner, the recorder will then signal Monitor A to come to the recorder's desk.

Once Monitor A has arrived, Monitor B will return to Room B. When Monitor A arrives, Monitor A and the recorder will carry the box of envelopes to room C. Room C contains locking boxes with identifying letters. The letters correspond to the letters on the inner envelopes. While the recorder observes, Monitor A will place each inner envelope in the box with the corresponding letter. All of the boxes will then be locked. The recorder will then return to the hallway and Monitor A will return to Room A.

Room A Participants Privately Open the Returned Envelopes. Monitor A will then point to one participant in Room A at a time to proceed to Room C. When called to go to Room C, each Room A participant will perform the following steps:

1. Gather all of his or her belongings since he or she will be asked to leave the building when done.

2. Enter Room C alone.

3. Open the envelope marked "KEY." Inside this envelope is a lettered key which will open the locked box with the corresponding letter. The inner envelope in the box is the same envelope that Room A participant started with. 
4. Go to the appropriate locked box, open it, take out the envelope, and remove the money.

5. Return the empty envelope to the box.

6. Lock the box.

7. Return the key to the envelope marked "KEY."

8. Drop the envelope marked "KEY" in the box just outside the door in the hallway, receive his or her $\$ 10$ compensation for participating in the experiment and be asked to leave the building.

Conclusion of Experiment. After everyone in Room A has left, the experiment is over and the two monitors will be paid $\$ 15$ for their participation.

Note about Dollar Bills. We will use e-dollars for this experiment. At the end of the experiment, your e-dollars will be converted into real dollars at a faceless teller. The conversion rate is one dollar for one e-dollar. 
This article has been cited by:

1. Cary A. Deck, Enrique Fatas, Tanya RosenblatEncouraging Replication of Economics Experiments 3-9. [Citation] [Full Text] [PDF] [PDF] 